\title{
A Critical Review of Spatial Predictive Modeling Process in Environmental Sciences with Reproducible Examples in $\mathbf{R}$
}

\section{Jin Li}

National Earth and Marine Observations Branch, Environmental Geoscience Division, Geoscience Australia, Canberra 2601, Australian Capital Territory, Australia; Jin.Li@ga.gov.au

Received: 22 February 2019; Accepted: 13 May 2019; Published: 17 May 2019

\begin{abstract}
Spatial predictive methods are increasingly being used to generate predictions across various disciplines in environmental sciences. Accuracy of the predictions is critical as they form the basis for environmental management and conservation. Therefore, improving the accuracy by selecting an appropriate method and then developing the most accurate predictive model(s) is essential. However, it is challenging to select an appropriate method and find the most accurate predictive model for a given dataset due to many aspects and multiple factors involved in the modeling process. Many previous studies considered only a portion of these aspects and factors, often leading to sub-optimal or even misleading predictive models. This study evaluates a spatial predictive modeling process, and identifies nine major components for spatial predictive modeling. Each of these nine components is then reviewed, and guidelines for selecting and applying relevant components and developing accurate predictive models are provided. Finally, reproducible examples using spm, an $\mathrm{R}$ package, are provided to demonstrate how to select and develop predictive models using machine learning, geostatistics, and their hybrid methods according to predictive accuracy for spatial predictive modeling; reproducible examples are also provided to generate and visualize spatial predictions in environmental sciences.
\end{abstract}

Keywords: spatial predictive models; predictive accuracy; model assessment; variable selection; feature selection; model validation; spatial predictions; reproducible research

\section{Introduction}

Spatial predictions of environmental variables are increasingly required in environmental sciences and management. Accurate spatially continuous data are required for environmental modeling, and for evidence-based environmental management and conservation. Such data are, however, usually not readily available and they are difficult and expensive to acquire, especially in areas that are difficult to access (e.g., mountainous or marine regions). In many cases, the spatial data of environmental variables are collected from point locations. Thus, spatial predictive methods are essential for generating spatially continuous predictions of environmental variables from the point samples. Moreover, predictive methods are increasingly being used to generate spatial predictions across various disciplines in environmental sciences [1-6] in parallel to recent advances in (1) computing technology and modeling techniques [7-9], and (2) data acquisition and data processing using remote-sensing techniques and geographic information systems. These advancements resulted in increasingly more environmental variables available for spatial predictive modeling. Consequently, more sophisticated spatial predictive modeling approaches are needed to deal with a large number of predictive variables.

Accuracy of spatial predictive model(s) is critical as it determines the quality of their predictions that form the scientific evidence to inform decision- and policy-making. Therefore, improving the accuracy 
by choosing an appropriate method and then identifying and developing the most accurate predictive model(s) is essential. It is often difficult to select an appropriate method for any given dataset because spatial predictive methods may be data- or even variable-specific and many factors need to be considered $[10,11]$. Although the development of hybrid methods of machine learning and geostatistics, and their application considerably improved predictive accuracy, these methods may also be data- or variable-specific [12-14]. For spatial predictive modeling, "no free lunch theorems" [15] are also applicable.

Furthermore, even with the right predictive method, it is a challenging task to identify and develop the most accurate predictive model(s). This is because the spatial predictive modeling process involves many factors or components $[10,16,17]$. In fact, only a portion of such factors were considered in many previous studies, which often led to sub-optimal or even misleading predictive models [11,18]. This not only presents an opportunity for scientists to develop and improve their predictive models, but also highlights the challenge of selecting relevant predictive variables from a large number of available predictive variables to form the most accurate predictive model. Heavy computations are often involved in identifying and selecting accuracy-improved predictive models for given datasets when the number of predictive variables is large, although high-performance computing facilities may be able to significantly alleviate this challenge.

This study aims to assist spatial modelers and scientists by critically reviewing the spatial predictive modeling process, developing guidelines for selecting the most appropriate spatial predictive methods and identifying and developing the most accurate predictive model to generate spatial predictions. In this study, I focus on spatial predictive models or spatial predictive modeling for generating spatially continuous predictions rather than on other models (e.g., inferential model) as discussed previously [19]. Consequently, the term accuracy in this study refers to the accuracy of predictive model(s) based on validation, and the term uncertainty refers to prediction uncertainty generated by predictive model(s). In this study, the term accuracy is used interchangeably with predictive accuracy. Furthermore, in this study, I mainly focus on the predictive methods for numerical data that are usually encountered in environmental sciences, with a brief discussion on categorical data. In this study, the following nine major components of spatial predictive modeling are identified and reviewed: (1) sampling design, sample quality control, and spatial reference systems; (2) selection of spatial predictive methods; (3) pre-selection of predictive variables; (4) exploratory analysis for variable selection; (5) parameter selection for relevant methods; (6) variable selection; (7) accuracy and error measures for predictive models (numerical vs. categorical); (8) model validation; and (9) spatial predictions, prediction uncertainty, and their visualization. In addition, reproducible examples using spm [20], an R package for machine learning, geostatistics, and their hybrid methods, are employed to demonstrate how to select and develop predictive models based on predictive accuracy for spatial predictive modeling; reproducible examples are also provided to generate and visualize spatial predictions in environmental sciences.

\section{Sampling Design, Sample Quality Control, and Spatial Reference Systems}

\subsection{Sampling Design}

Although samples are usually collected, stored, and ready to use for spatial predictive modeling, sometimes samples are not available and need to be collected. In the latter situation, a sampling design needs to be produced. In this study, I focus on sampling designs over space. To collect samples from a survey area for a certain survey purpose, a sampling design is an important step and must be created. A good sampling design ensures that data collected from a survey are capable of answering relevant research questions. Better designs, such as spatially stratified sampling designs, will also be as precise and efficient as possible [21,22]. Many methods were developed to generate sampling designs [23-26]. They typically fall into four main categories: (1) non-random sampling design; (2) unstratified random sampling design; (3) stratified random sampling design; and (4) stratified random sampling design with prior information. 
The non-random sampling design can be ad hoc sampling based on expert knowledge, purely opportunistic when a certain type of environmental condition becomes available, or systematic sampling. This type of sampling design was applied to many surveys [27-29]. For spatial predictive modeling, this method is not recommended for future studies. However, an interesting comparison of non-random sampling designs was reported for spatial predictive modeling [26]; it may provide some useful clues for sampling designs (e.g., lattice plus close pairs) for spatial predictive modeling.

The unstratified random sampling design is that sampling locations are randomly selected. This can be (1) an unstratified equal probability design, or (2) an unstratified unequal probability design $[30,31]$. This type of sampling design is not recommended for spatial predictive modeling studies because (1) spatial information is available for sampling design and thus spatially stratified sampling design should be used as discussed below, and (2) it may even be over-performed by the non-random design (i.e., lattice design) [26].

The stratified random sampling design is often used when additional information is available. Such information can be spatial (or location) information, elevation, bathymetry, or geomorphological information. For spatial predictions, such information is important and should be considered when designing a survey for a region. A few recently developed randomized spatial sampling procedures were reviewed and compared using simple random sampling without replacement as a benchmark for comparison [22]. This study provided some empirical evidence for the improvement of sampling efficiency from using these designs and provided some guidance for choosing an appropriate spatial sampling design [22]. Furthermore, some R packages, such as spsurvey [31], GSIF [32], spcosa [33], clhs [34], and BalancedSampling [35], were developed for this type of sampling design. The stratified random sampling designs with spatial information (i.e., spatially stratified sampling design) are increasingly being used in practice [28,36,37].

The stratified random sampling design with prior information is a new development for sampling over a space. It incorporates the locations of legacy sites into new spatially balanced survey designs to ensure spatial balance among all sample locations [21]. It can be seen as a stratified unequal probability design. An R package, MBHdesign, was developed for this method [38].

\subsection{Sample Quality Control}

Sample quality is vitally important because samples provide the fundamental information for spatial predictive modeling. Many factors may affect sample quality and they are usually dataset-specific $[39,40]$. Consequently, relevant factors need to be identified for each dataset and then relevant data quality control $(\mathrm{QC})$ criteria need to be developed to $\mathrm{QC}$ the dataset $[39,40]$ prior to undertaking spatial predictive modeling. For example, in Geoscience Australia's Marine Samples Database (MARS; http://dbforms.ga.gov.au/pls/www/npm.mars.search), seabed sediment samples were initially quality controlled prior to and after entering the database according to various criteria [12,41]. However, the quality of the samples was still affected by many factors, including data credibility (e.g., non-dredge), data accuracy (e.g., non-positive bathymetry), completeness (e.g., no missing values), etc.; hence, data quality control approaches were developed to QC the samples of seabed mud content and sand content [12,41]. These approaches may provide examples about how to identify relevant factors and develop possible data QC criteria for a given dataset. In some instances, data noise may result from repeated measurements, and certain rules may need to be developed to clean such samples based on professional knowledge [42]. Moreover, exploratory analysis can be used to further detect abnormal samples, as detailed in Section 5.

\subsection{Spatial Reference Systems}

To generate spatial predictions (i.e., spatially continuous data) for a region using spatial predictive models, two types of georeferenced data are required: (1) point samples of response and predictive variables; and (2) grid data of predictive variables. Such georeferenced data are often stored according to various spatial reference systems [43]. The spatial reference system used to project or store the spatial 
information is often assumed to have certain effects on the performance of predictive models; thus, in practice, various spatial reference systems were used to minimize such effects [43]. When a study area is small and within one particular UTM zone, spatial data are often projected using either the UTM zone or an appropriate projection system; when the study area is spanning multiple UTM zones, the existing geographic coordinate system (i.e., WGS84) or another appropriate projection system can be used.

Although the spatial reference system by which the spatial information is stored is often considered as a potential source of error for spatial predictive modeling, a series of studies demonstrated that the effects of spatial reference systems on the performance of spatial predictive methods (i.e., inverse distance weighting and ordinary kriging) are negligible for areas at various latitudinal locations (up to $70 \mathrm{dd}$ ) and spatial scales (i.e., regional and continental) [43-45]. Therefore, it was recommended that spatial reference system selection and re-projection can be removed for spatial predictive modeling for areas with latitude less than $70 \mathrm{dd}$, and spatial data can be modeled in WGS84 or the spatial projection system already used for the data. Although new spatial reference systems (e.g., DGGS [46]) may be developed to remedy various limitations of existing ones, the above recommendation may still be applicable as discussed previously on why the effects of spatial reference systems on the predictive accuracy are negligible [43-45].

\section{Selection of Spatial Predictive Methods}

\subsection{Spatial Predictive Methods}

For spatial predictive modeling, there are many methods available [3]. Previously, over 20 spatial predictive methods were grouped into (1) non-geostatistical methods (e.g., inverse distance weighting (IDW)), (2) geostatistical methods (e.g., ordinary kriging (OK)), and (3) combined or hybrid methods [10]. Collectively, these methods are largely non-machine learning methods and a small portion of these methods, like regression tree (RT) and linear regression models (LM), use secondary information.

When sufficient secondary information is available, a number of other methods could be used. These methods include traditional statistical methods, machine learning methods, the hybrid methods of traditional statistical methods and geostatistical methods, and the hybrid methods of machine learning and geostatistical methods (Table 1). These methods were applied or compared in various spatial predictive modeling studies [12,41,47-55]. Of these methods, random forest (RF), hybrid method of RF and OK (RFOK), and hybrid method of RF and IDW (RFIDW) were among the most accurate methods in these applications. Generalized boosted regression modeling (GBM), hybrid method of GBM and OK (GBMOK), and hybrid method of GBM and IDW (GBMIDW) showed great potential based on our unpublished study. In the current study, these methods are presented in three main groups: (1) non-machine learning methods; (2) machine learning methods; and (3) the hybrid methods. 
Table 1. Spatial predictive methods using predictive variables [6,12,41,48-55].

\begin{tabular}{|c|c|c|c|}
\hline \multicolumn{2}{|c|}{ Non-Machine Learning Method and Hybrid Methods } & \multicolumn{2}{|c|}{ Machine Learning Method and Hybrid Methods } \\
\hline Non-machine learning method & Hybrid methods & Machine learning method & Hybrid methods \\
\hline Generalized additive models & & Cubist & Cubist and OK (cubistOK) \\
\hline Generalized least squares trend estimation (GLS) & GLS and OK & Generalized boosted regression modeling (GBM) & GBM and IDS (GBMIDS) \\
\hline Generalized linear models (GLM) & GLM and IDW (GLMIDW) & & GBM and OK (GBMOK) \\
\hline \multirow{7}{*}{ GLM with lasso or elastic net regularization } & GLM and OK (GLMOK) & General regression neural network (GRNN) & $\begin{array}{l}\text { GRNN and IDS } \\
\text { (GRNNIDS) }\end{array}$ \\
\hline & & & $\begin{array}{l}\text { GRNN and OK } \\
\text { (GRNNOK) }\end{array}$ \\
\hline & $\begin{array}{l}\text { Linear models and OK } \\
\text { RT and IDS (RTIDS) }\end{array}$ & $\begin{array}{c}\text { Multivariate adaptive regression splines } \\
\text { Naïve Bayes }\end{array}$ & \\
\hline & RT and OK (RTOK) & Random forest (RF) & RF and IDS (RKIDS) \\
\hline & & & RF and OK (RKOK) \\
\hline & & Support vector machine (SVM) & SVM and OK (SVMOK) \\
\hline & & & SVM and OK (SVMIDS) \\
\hline
\end{tabular}




\subsection{Selecting Spatial Predictive Methods}

Selection of appropriate spatial predictive methods for a response variable (or dependent variable, or primary variable in geostatistics) is critical. For data without predictive variables, geostatistical methods are the only methods that can be used. Method selection was discussed and guidelines were developed for using geostatistical methods in various studies [16,56-61]. A decision tree was developed for selecting the most appropriate method from a pool of 25 spatial predictive methods according to the availability and nature of data and the expected predictions, together with the features of each method [10]. However, it was argued that there was no simple answer regarding the choice of appropriate geostatistical methods, because the hallmark of a good geostatistical modeling work is customization of the approach to the dataset at hand [56]. This suggests that "no free lunch theorems" [15] are also applicable for spatial predictive modeling using geostatistical methods. Joint application of two spatial predictive methods might produce additional benefits such as the combined procedures in previous studies [10,62-64].

For data with predictive variables, there are many options available. It is often difficult to select an appropriate method because the performance of spatial predictive methods depends on many factors, including the assumptions and properties of each method, the nature and spatial structure of data for the response variable, sample size and distribution, the availability of predictive variables, availability of software, computational demands, and many other factors [10,11]. All of these factors need to be considered when making an appropriate selection.

Moreover, if more than one method can be applied, model comparison techniques such as cross-validation in combination with the measures of predictive error or accuracy can be used to select a method. This selection technique not only selects the most appropriate method but also the most accurate predictive model that can maximize the predictive accuracy $[12,65,66]$. This selection technique can be applied to methods irrespective of whether they use predictive variables.

\section{Pre-Selection of Predictive Variables}

Predictive variables are termed predictor variables, independent variables, predictors, and features. They are also called secondary variables/information in geostatistics. They are essential for spatial predictive methods that use predictive variables.

\subsection{Principles for Pre-Selection of Predictive Variables and Limitations}

Principles for pre-selecting predictive variables may change with disciplines. For environmental sciences, the main principle is that predictive variables need to be closely related to the variable to be predicted (i.e., the response variable) $[67,68]$; ideally, they should be causal variables, or variables directly caused by the response variable (e.g., optical reflectance of vegetation types, backscatter of seabed substrates). They are usually identified based on expert or professional knowledge. However, in many cases, it is hard to know what the causal variable(s) is (are) for a response variable. Proxy (or surrogate) variables are often used instead of causal variable for spatial predictive modeling. Again, they are usually identified based on expert or professional knowledge [69]. Certainly, predictive models can use causal variables, proxy variables, or both if causal variables are not all available.

When the accuracy of a resultant predictive model is unexpectedly poor, then we may need to consider that we may have missed some important predictive variables, for which we may have no knowledge or even awareness (e.g., hidden variables [70]). Further actions are required to expand the professional knowledge pool in order to identify such possible predictive variables.

For spatial predictive modeling, the selection of potential predictive variables is even more challenging. This is because the selection could be constrained by certain factors. For example, predictive variables need to be continuously available for a target region. Spatial resolution is also a critical issue as the resolutions of various predictive variables need to meet the desired resolution for the final predictions, although they can be rescaled. Sometimes, even though we know the possible 
causal predictive variables based on expert or professional knowledge, they may not meet these requirements and cannot be used for spatial predictive modeling. This is particularly true in marine environmental sciences.

\subsection{Predictive Variables for Environmental Sciences}

For terrestrial environmental modeling, many predictive variables are available. Many previous applications provided examples of variables used for terrestrial environmental modeling [13,42,49-51, $53,67,71,72]$.

In contrast, the information of predictive variables is often scarce for marine environmental modeling. In many cases, proxy variables are usually used for predictive modeling $[69,73]$. For example, to predict the spatial distribution of seabed sediments for Australian Exclusive Economic Zone (AEEZ) at a resolution of 0.01 or 0.0025 degrees, only a few predictive variables were available for the whole AEEZ [12,41,74] (Table 2). For spatial predictions over smaller areas, quite often more predictive variables became available at desired resolution such as for seabed sediment [4,75-77], seabed hardness [78-80], and sponge species richness [6,81] (Table 2). Bathymetry and backscatter were also used to predict seabed sediment at local scale [82]. Some derived information may be used as predictive variables. For example, in Table 2, predictive variables 5-13 were derived from bathymetry (bathy), while predictive variables 15-19 were derived from backscatter (bs). Some other variables were used for seabed grain size at small scale [48]. In addition, many variables were reviewed $[69,83]$ and could be used for marine environmental modeling. Fuzzy geomorphic features were also used for spatial predictive modeling at local scales $[77,84]$. 
Table 2. A list of predictive variables used for some marine environmental variables.

\begin{tabular}{|c|c|c|c|c|c|}
\hline No & Predictive Variables & Seabed Sediment/Grain Size & Seabed Hardness & Sponge Species Richness & Window/Kernel Size(s) \\
\hline 1 & Longitude (long) & yes & yes & yes & \\
\hline 2 & Latitude (lat) & yes & yes & yes & \\
\hline 3 & Distance to coast (dist) & yes & & yes & \\
\hline 4 & Bathymetry (bathy) & yes & yes & yes & \\
\hline 5 & Local Moran's I from bathymetry & yes & yes & yes & yes \\
\hline 6 & Mean curvature & yes & & & yes \\
\hline 7 & Planar curvature & yes & yes & yes & yes \\
\hline 8 & Profile curvature & yes & yes & yes & yes \\
\hline 9 & Relief & yes & yes & yes & yes \\
\hline 10 & Rugosity (or surface, surface complexity) & yes & yes & yes & yes \\
\hline 11 & Slope & yes & yes & yes & yes \\
\hline 12 & Topographic or bathymetric position index (tpi or bpi) & yes & yes & yes & yes \\
\hline 13 & Fuzzy morphometric features & yes & & & yes \\
\hline 14 & Backscatter (bs) 10-36 & yes & yes & yes & \\
\hline 15 & Entropy from bs & & & yes & yes \\
\hline 16 & Homogeneity from bs & & yes & yes & yes \\
\hline 17 & Local Moran's I from bs & & yes & yes & yes \\
\hline 18 & Prock from bs & & yes & & \\
\hline 19 & Variance from bs & & yes & yes & yes \\
\hline 21 & Mean tidal current velocity & yes & & & \\
\hline 22 & Peak orbital velocity of waves at seabed & yes & & & \\
\hline 23 & Roughness from bathy * & yes & & & \\
\hline 24 & Roughness from bs * & yes & & & \\
\hline 25 & Sobel filter from bathy $\#$ & yes & & & \\
\hline
\end{tabular}

* The difference between the minimum and maximum of cell and its eight neighbors [48]. " A directional filter that emphasizes areas of large spatial frequency (edges) running horizontally $(X)$ or vertically $(Y)$ across the image $[48]$ 


\section{Exploratory Analysis for Variable Pre-Selection}

\subsection{Non-Machine Learning Methods}

Exploratory analysis is often used to detect the relationships between the response variable and predictive variables for non-machine learning methods, such as LM, generalized linear models (GLM), and kriging with an external drift (KED). By applying such analysis, people intend to find data nature and structure [85]. Key issues may include the identification of (1) outliers, (2) homogeneity in variance of response variable, (3) data distribution of response variables including normality, (4) collinearity (i.e., the correlation among predictive variables), (5) relationships or response curves of response variable to predictive variables, (6) how strong the relationships are between response variable and predictive variables, (7) possible interactions among predictive variables, (8) independence of a response variable, whether temporally, spatially, or both, and (9) source of random errors, which may lead to a mixed-effect model or additional predictive variable(s) [71]. On the basis of the above analyses, certain actions can be taken to deal with relevant samples or variables. For instance, some predictive variables can be removed if their correlations with the response variable are low. However, it would be wise to let the variable selection process determine which variables should be removed because some variables may be important predictive variables even with low correlations. Highly correlated predictive variables, usually determined based on correlation coefficient $(r)$ or variance inflation factor (VIF), can also be eliminated to reduce the collinearity, although caution should be taken for this exercise $[9,86]$. Relevant issues about collinearity were also discussed [87]. Some predictive variables may need to be specified to their second or third orders if a non-linear relationship is detected. Moreover, some interactions may need to be considered and tested.

\subsection{Machine Learning Methods and Hybrid Methods}

For machine learning methods, exploratory analysis is useful for understanding data and interpreting modeling results [78]. However, some roles of exploratory analysis for non-machine learning methods are no longer needed for machine learning methods. This is because machine learning methods, like RF, are free of assumptions on the data distribution and can handle non-linear relationships and interactive effects $[88,89]$. They can also handle highly correlated predictive variables $[6,47]$. Furthermore, the use of highly correlated predictive variables is encouraged for RF because they may be able to make a meaningful contribution to improving predictive accuracy [6].

\subsection{Hybrid Methods}

For the hybrid methods, exploratory analysis is as useful as for the aforementioned methods. The residuals of a detrending method (e.g., GLM, RF) are assumed to be normal if kriging methods are applied. Thus, the residuals need to be analyzed to check this assumption [12,41].

\section{Parameter Selection}

\subsection{Parameter Selection for Non-Machine Learning Methods}

For non-machine learning methods, I mainly focus on two commonly used methods [11], IDW and kriging (e.g., OK). For IDW, it is really dependent on the selection of appropriate values for a power parameter and the number of nearest observations, which can be selected based on their resultant predictive accuracy $[41,90]$. The smoothness of the estimated surface increases as the value of power parameter increases [91]; however, manipulating the power parameter to smooth the predictions and to produce visually pleasant maps does not warrant the quality of the resultant predictions and is not recommended.

For kriging methods, a number of parameters, including window size, and isotropy and anisotropy of data, need to be considered, as well as the variogram model and its parameters. Data transformation needs to be considered when the data are skewed and anisotropic. Three methods of data transformation 
(i.e., logarithms, standardized rank order, and normal scores) can be employed to reduce the skewness [74, 92]. Some other methods, such as Box-Cox transformation [82], arcsine [88], square-root transformation [47], and double square root or square root and $\log$ [12], can be used to normalize the data. The selection of these transformation and normalization methods is largely data-dependent and careful examination should be taken. The selection can also be determined according to their effects on the predictive accuracy.

In addition, for anisotropy, non-stationary methods like KED should be used in cases with a general anisotropy or trend (i.e., drift) [75]. If different types of non-stationarity exist, application of different spatial predictive methods to each type may improve predictive accuracy [93].

The parameter selection for these methods can be determined according to the predictive accuracy of resultant predictive models. This is demonstrated in Section 11.

\subsection{Parameter Selection for Machine Learning Methods}

For machine learning methods, RF and GBM are considered. For RF, relevant parameters are mtry, ntree, and so on [94], while, for GBM, these include n.trees, learning.rate, interaction.depth, bag.fraction, and so on [95]. Some commonly used default parameter values can be used as they are quite often optimal $[94,96]$, except the distribution parameter for GBM. The distribution parameter for GBM should be based on data type of the response variable; for example, Poisson should be used for count data. Relevant parameters can also be selected based on cross-validation $[41,48,96]$.

\subsection{Parameter Selection for Hybrid Methods}

The parameter selections for the above non-machine learning methods and machine learning methods are equally applicable to relevant hybrid methods.

\section{Variable Selection}

For machine learning methods, variable selection is termed feature selection, while, for non-machine learning methods, it is often called model selection. However, model selection often leads to the most parsimonious fitted model rather than the most accurate predictive model [6]. In this study, we use the term "variable selection" for both non-machine learning and machine learning methods to identify and develop the most accurate spatial predictive model(s).

Variable selection is important for many predictive methods, although it is not required for all methods. For instance, classification and regression trees [97] and LIVES [98] are exempt from variable selection. However, as per all other methods, they assume that the predictive variables used are informative and not misleading because they treat each predictive variable as equally important. Thus, misleading predictive variables may considerably reduce predictive accuracy as discussed previously [98]. The variable selection procedure for machine learning methods and their hybrid methods is fundamentally different from the procedure for non-machine learning methods $[47,79,99]$. For geostatistical methods like IDW and OK, no variable selection is required, and it is really about the selection of appropriate values for relevant parameters, as discussed in Section 6. In this section, I focus on the following three methods: (1) GLM; (2) RF; and (3) GBM. This is because of their wide applications, robustness, or the recent developments in variable selection techniques for these methods.

For GLM, there are many methods available in $R$ for variable selection [100-103]. These methods may include (1) stepAIC or step; (2) dropterm, drop1, or add1; (3) anova; (4) regsubsets; and (5) bestglm [100,102,103]. The application of these methods for spatial predictive modeling can be seen in recent studies $[6,104]$. Variables selected based on these methods may form the most parsimonious model, but the model may have low predictive accuracy or even be misleading $[6,104]$, with the exception that bestglm is promising if cross-validation, instead of Akaike's information criterion (AIC) or Bayesian information criterion (BIC), is used for information criteria [104]. Alternatively, the variable selection for GLM can also be based on variables selected by other method such as RF [71]. It was found that traditional variable selection methods are unsuitable for identifying GLM predictive models, and joint application of RF and AIC can select accuracy-improved predictive models [6]. This highlights the importance of differentiating variable 
selection for predictive modeling [6] from variable selection for hypothesis testing [99] or inferential modeling [19]. The common mistakes associated with incorrectly distinguishing data analytic types were briefly summarized and discussed previously [19].

For RF, variable selection methods may include (1) variable importance (VI) [78], (2) averaged variable importance (AVI) [79], (3) Boruta [105], (4) knowledge informed AVI (KIAVI) [6,79], (5) recursive feature selection (RFE) [106], and (6) variable selection using RF (VSURF) [107]. Of these methods, KIAVI is recommended because it outperforms all other variable selection methods $[6,79,104,108]$.

For GBM, variables can be selected in terms of the relative influence $[95,108]$. The recursive feature selection [106] can also be used for variable selection.

Two concepts were proposed for variable selection: important and unimportant predictive variables based on the predictive accuracy $[6,79]$. They were defined as follows:

1. Important variable based on the predictive accuracy (IVPA). This refers to the variable for which exclusion during the variable selection process would reduce the accuracy of a predictive model based on cross-validation. It may be more appropriate to call it predictive accuracy boosting variable (PABV).

2. Unimportant variable based on the predictive accuracy (UVPA). This refers to variables for which exclusion during the variable selection process would increase the accuracy of a predictive model based on cross-validation [6,79]. It may be more precise to call it predictive accuracy reducing variable (PARV).

Application of relevant variable selection methods and concepts can further improve the accuracy of predictive models [6,79]; this is demonstrated in Section 11. Although these concepts were developed based on RF and its hybridization with geostatistical methods, they can be equally applied to any other predictive methods.

\section{Accuracy and Error Measures for Predictive Models}

\subsection{Relationship between Observed, Predicted, and True Values}

Predictive accuracy is about the differences between observed and predicted values that are derived based on validation methods [18]. However, it is often questioned what the differences between the predicted values and true values are. Since the true values are mostly unknown, the observed values are used to validate predictive models. For an observed value, it may be again different from its corresponding true value. The difference between the true value and observed value is the error associated with the observed value. Let us refer to this error as an observational error that is the sum of random error associated with observed variable, sampling error, and measuring error. The sampling and measuring errors are the sum of errors resulting from various factors that may affect the accuracy of observation (i.e., measurement) and change with the variable observed. Let us take seabed sediment as an example; the factors may include sampling design, the position accuracy of survey vessel, equipment used for sample collection, field operation, sample storage, sample processing procedure and analysis in laboratory, data entry, etc. However, how much error can be attributed to each of these factors is unknown in most cases. Hence, we have to use observed and predicted values to assess the predictive accuracy in practice.

\subsection{Error and Accuracy Measures of Predictive Models}

Many error and accuracy measures were developed to assess the accuracy of predictive models for numerical data $[65,109,110]$. Some of these error and accuracy measures were assessed and their limitations were previously discussed $[3,18]$. Of these error and accuracy measures, VEcv (i.e., variance explained by a predictive model based on cross-validation) measures how accurate the predictive model is and was proven to be independent of unit, scale, data mean, and variance [18,111], while root mean squared error (RMSE) measures how wrong the predictive model and the resultant predictions 
can be. Therefore, VEcr and RMSE are recommended for numerical predictions. Legates and McCabe's E1 (E1) was recommended for numerical data as well [111]. The commonly used measure, $r$ or $r^{2}$, is not recommended because it is an incorrect measure of predictive accuracy [111].

For categorical data, correct classification rate (CCR), kappa (kappa), sensitivity (sens), specificity (spec), and true skill statistic (TSS) are often recommended [112,113]. RMSE is also used for presence and absence data [114]. One commonly used measure, area under the curve (AUC) (or receiver operating characteristics (ROC)), is not recommended for reasons previously highlighted [112,115].

\section{Model Validation}

\subsection{Model Validation Methods}

The accuracy of predictive models is critical as it determines the quality of the resultant predictions. The accuracy is often assessed based on model validation methods that may include the following:

1. Hold-out validation;

2. K-fold cross-validation;

3. Leave-one-out cross-validation;

4. Leave-q-out cross-validation;

5. Bootstrapping cross-validation;

6. Using any new samples that are not used for model training.

In environmental sciences, the most commonly used validation methods are hold-out and leave-one-out [18]. However, of these validation methods, five- or 10-fold cross-validation was recommended $[7,116]$.

\subsection{Randomness Associated with Cross-Validation Methods}

Although a five- or 10-fold cross-validation was recommended to evaluate the performance of spatial predictive models [116], the datasets are randomly generated for each fold of the cross-validation change when the process is repeated. Thus, the randomness associated with the cross-validation would produce predictive accuracy or error measures that change with each iteration of the cross-validation [47]. To reduce the influence of the randomness on predictive accuracy (i.e., to stabilize the resultant performance measures), the cross-validation needs to be repeated (e.g., 100 times) $[47,74,78]$. The choice of this iteration number is data-dependent and can be determined based on the method used in previous studies [47,78].

\section{Spatial Predictions, Prediction Uncertainty, and Their Visualization}

\subsection{Spatial Predictions}

In spatial predictive modeling, the goal is not only to develop the most accurate predictive model, but more importantly to generate spatial predictions. The spatial predictions are usually produced using the most accurate predictive model developed according to the above procedures. To make predictions, in addition to the spatial predictive model, we need relevant information of each model predictive variable to be available at each grid cell at a desired resolution. When all this information is prepared, the spatial predictions can then be generated. The predictions contain three columns, i.e., longitude, latitude, and predictions. Sometimes, uncertainty of the predictions can be produced.

\subsection{Prediction Uncertainty}

Prediction uncertainty in environmental modeling may refer to various aspects of the modeling process and is used to encompass many concepts [117-120]. It can result from various sources or factors as previously discussed $[17,120,121]$. In this study, the uncertainty which is produced by a predictive model is about spatial predictions. Prediction uncertainty is increasingly required for decision-making 
and many methods are used to produce such uncertainty. In this study, I focus on the uncertainty produced by some commonly used methods: OK, LM, and RF.

For OK, prediction variances can be produced [58]. However, it was shown that the variances produced are independent of the actual predicted values [122]. Thus, the resulting variances should not be used to measure uncertainty, although many studies used them for such purpose. Since they reflect the variations in spatial departures among samples, they can be used as good indicators where samples are sparse and, thus, may provide useful information for selecting future sampling locations.

For LM, prediction uncertainty (i.e., prediction intervals) produced are much wider than confidence intervals of a model fitted [101]. Such uncertainty, however, has little to do with the predictive accuracy of the model. For instance, it was found that the models developed according to goodness of fit could be misleading when they were used as predictive models [6]; hence, its prediction uncertainty could also be misleading, and further studies are recommended.

For RF, many types of uncertainty could be produced, which actually reflect the difference in sampling strategies [123-126]. For example, prediction uncertainty produced for RF in a previous study based on Monte Carlo resampling [127] was, in fact, measuring the variation in predictions among individual trees rather than by RF. A further example for RF is that an ensemble of equally probable realizations was generated and the differences amongst the realizations were used as a measure of uncertainty [128]. This type of uncertainty only measures the differences among the results of various runs of $\mathrm{RF}$, that is, measuring the difference resulted from the randomness associated with each run. Hence, these values do not relate to predictive accuracy and do not measure prediction uncertainty.

In addition, for any of the spatial predictive methods above, predictive errors based on validation can be produced for a predictive model developed. However, this leads to only one error value, and all predictions would have the same uncertainty value if it is used as an uncertainty measurement [129].

It is apparent that the uncertainty values produced above are either not measuring prediction uncertainty, or they depend on various factors as discussed above. This consequently results in the need to question the uncertainty of uncertainty. In short, how to assess prediction uncertainty needs further study. Any uncertainty measures that can incorporate the information of predictive accuracy are worth further investigation and recommended for future studies.

\subsection{Visualization}

Spatial predictions can be visualized using various tools, most commonly ArcGIS and QGIS. The function, spplot, in $\mathrm{R}$ is often used to plot the distribution of spatially continuous predictions [59]. The R package, raster, can also be used for such purpose [130]. Joint application of $\mathrm{R}$ and Google Earth can be used to visualize the predictions. In this study, I demonstrate how to use the latter approach along with spplot to visualize the predictions as below.

\section{Reproducible Examples for Spatial Predictive Modeling}

In this section, reproducible examples using spm, an R package, are provided to demonstrate how to select and develop a predictive model according to the guidelines and recommendations provided in the previous sections for spatial predictive modeling in environmental sciences. The predictive model to be used was developed using RFOK [74], where data preparation, including pre-selection of predictive variables, relevant parameter selection, variable selection, and model validation, was detailed. Seabed gravel content samples in the Petrel sub-basin, northern Australia marine margin are used to demonstrate how to select relevant parameters, test the predictive accuracy, and generate and visualize spatial predictions. These examples for RFOK can be easily extended to other predictive methods including IDW, OK, RF, GBM, RFIDW, GBMOK, GBMIDW, RFOKRFIDW, and GBMOKGBMIDW by replacing $r f o k c v$ and its associated parameters with relevant functions and parameters for these methods in spm. 


\subsection{Accuracy of a Predictive Model for Seabed Gravel Content}

In a previous predictive model [74], a spherical variogram model and a searching window size of 12 were used. The accuracy of this predictive model [74] can be shown using the rfokcv function in spm as shown below. To stabilize the accuracy derived, I repeat the cross-validation 100 times, which can be determined using the methods discussed in Section 9.2.

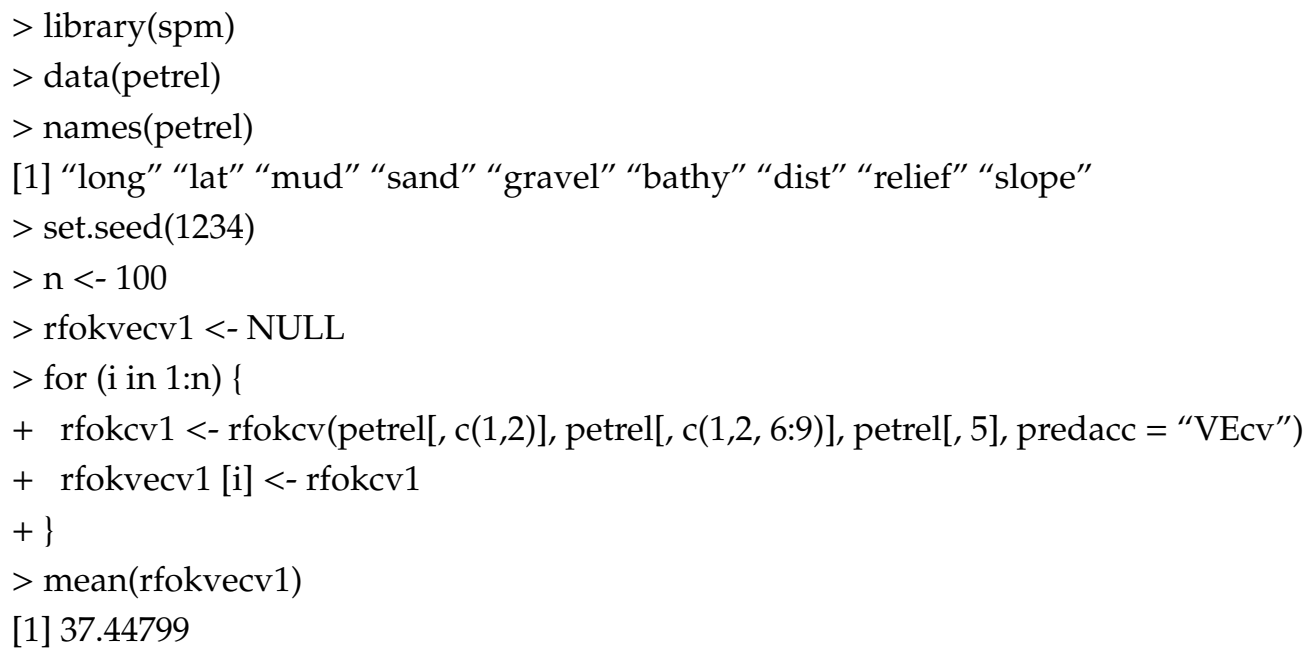

It suggests that the predictive accuracy is $37.4 \%$ in terms of VEcv.

\subsection{Parameter Selection}

The $r f o k c v$ function in spm is used to demonstrate how to select the best parameters for a predictive model (by using above predictive model as an example), and to check if the parameters used are optimal.

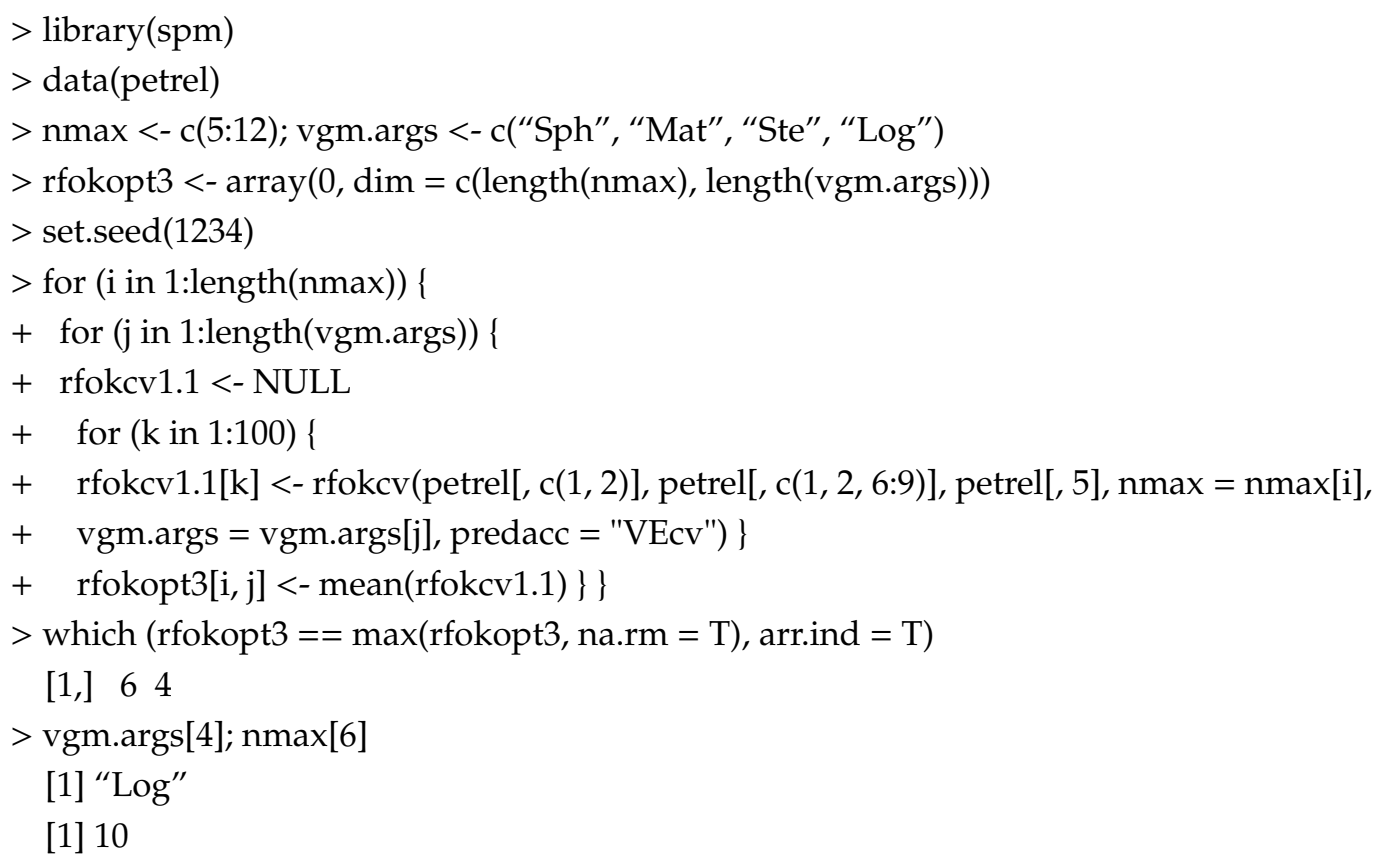

The results suggest that the model would achieve the best predictive accuracy if "Log" is used for variogram modeling, and the 10 nearest samples are used for nmax. Of course, a different range may be used to choose the best nmax, and other variogram models can also be tested if needed.

We can use $r f o k c v$ in $s p m$ to assess the accuracy of RFOK by using the parameters identified above. 


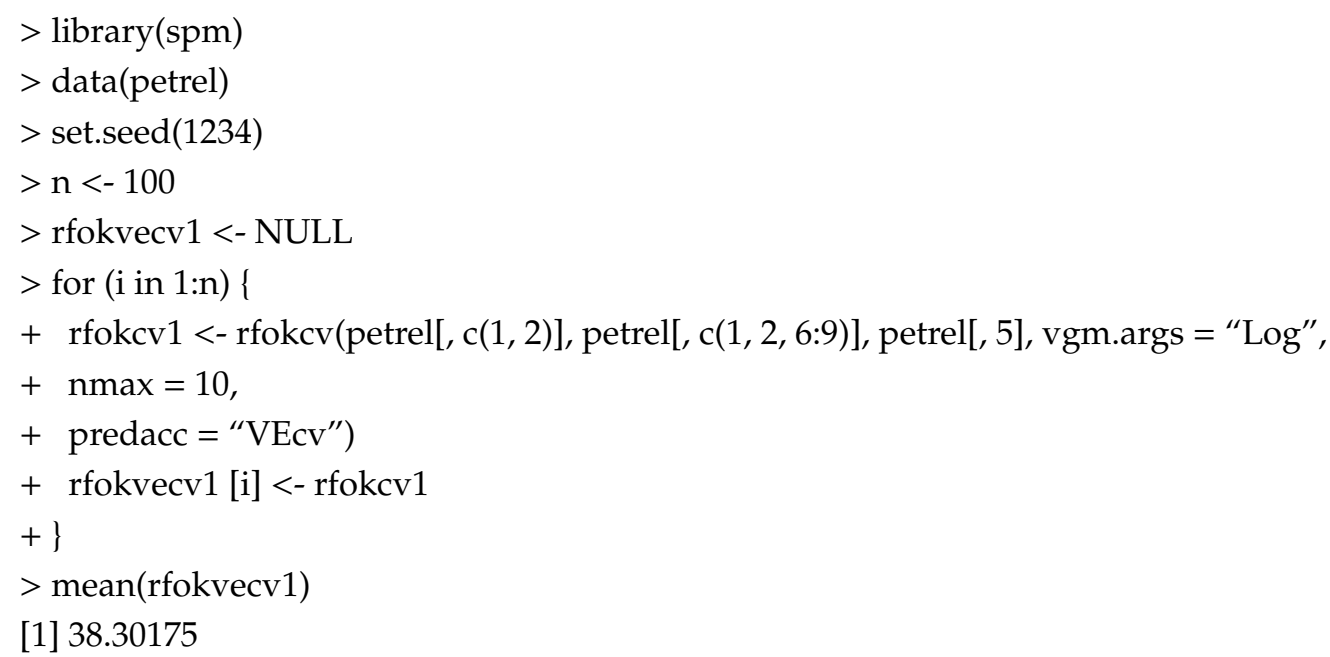

This finding suggests that the overall averaged accuracy of the RFOK predictive model for seabed gravel content in terms of VEcv is $38.3 \%$, higher than that of the previous model. This demonstrates that the parameters used previously are not optimal and that parameter selection improved predictive accuracy.

\subsection{Predictive Variable Selection}

In this study, we use the predictive variables previously identified [74], where the predictive variables were selected based on VI. Since then, more advanced variable selection methods for RF, RFOK, and RFIDW, such as AVI, KIAVI, PABV, and PARV [6,79], were developed. Application of these model selection methods and concepts may further improve the predictive accuracy of the model above. It is apparent that latitude (lat) is a PARV, as shown in the previous study [74]; thus, the removal of lat is expected to improve the predictive accuracy. This can be demonstrated below.

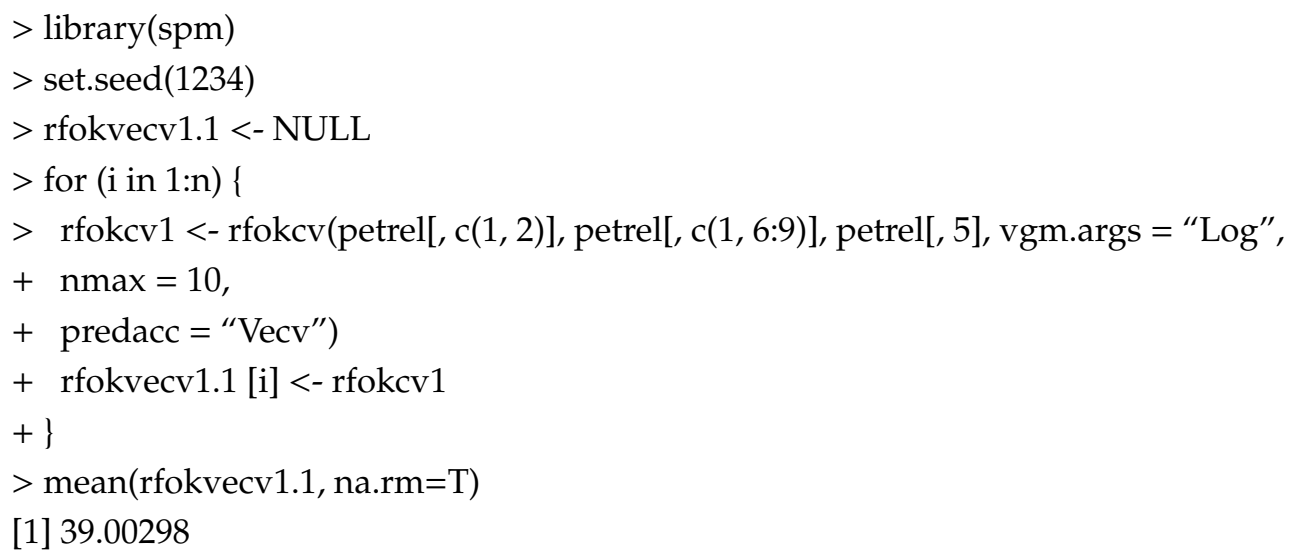

A further improvement in predictive accuracy is achieved after applying PARV. This further demonstrates the role of variable selection, especially the importance of newly developed variable selection methods.

\subsection{Generation of Spatial Predictions}

The predictive model developed above can be used to generate spatial predictions. The function rfokpred in spm is used to produce the predictions.

$>$ set.seed(1234)

$>$ library(spm)

$>$ data(petrel); data(petrel.grid) 
$>\operatorname{rfokpred} 1<-\operatorname{rfokpred}(\operatorname{petrel}[, \mathrm{c}(1,2)]$, petrel[, $\mathrm{c}(1,6: 9)]$, petrel[, 5], petrel.grid[, $\mathrm{c}(1$, $2)], \quad+$ petrel.grid, ntree $=500$, nmax $\left.=10, \operatorname{vgm} . \operatorname{args}=\left({ }^{\prime \prime} \log ^{\prime \prime}\right)\right)$

$>$ names(rfokpred1)

[1] "LON" "LAT" "Predictions" "Variances"

The output dataset has four columns named longitude, latitude, predictions, and variances. Please note that the uncertainty information (i.e., variances) is produced for readers interested; however, be aware of the various limitations as discussed in Section 10 when using such information.

\subsection{Visualisation of Spatial Predictions}

Joint application of $\mathrm{R}$ and Google Earth can be used to visualize the predictions generated above.

$>$ library(sp); library(plotKML)

$>$ rfok1 <-rfokpred1

$>$ gridded(rfok1) $<-\sim$ longitude + latitude

$>$ proj4string(rfok1) <- CRS(“+proj=longlat +datum=WGS84")

$>$ plotKML $($ rfok1, colour_scale $=$ SAGA_pal[[1]], grid2poly $=$ TRUE $)$

The resultant map is shown in Figure 1a. One of the advantages of using R and Google Earth is that it can place the prediction map into the context map by Google Earth, which provides additional information to final users. However, the labels of longitude and latitude are hard to place in Figure 1a. If these labels are required, spplot can be applied to the above gridded data as shown below (Figure 1b).

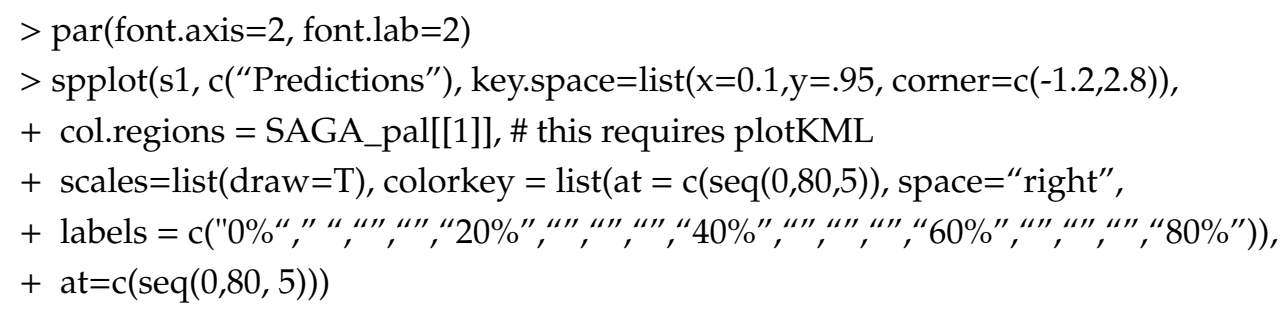

With regard to the prediction map, it is obvious that there are artefacts (e.g., sharp vertical changes associated with longitude) in the predictions. These artefacts may disappear or be alleviated if more variables could be used; in other words, different predictive variables should be tested according to the recently development in variable selection $[6,79]$, as discussed in Section 7.

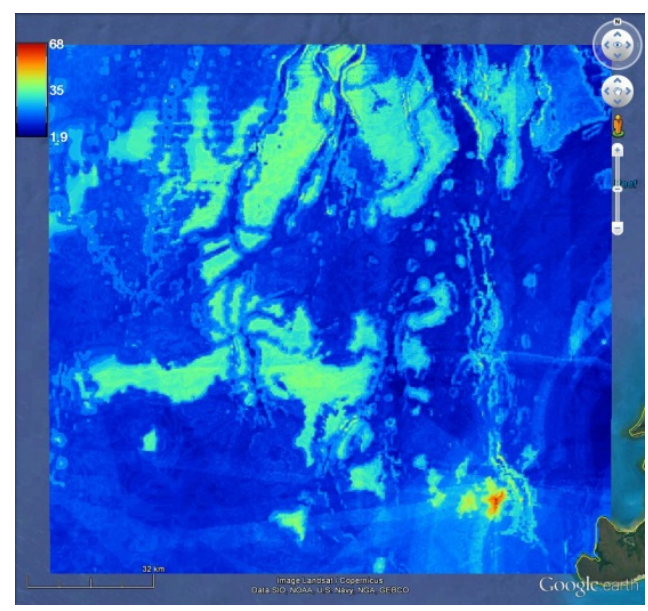

(a)

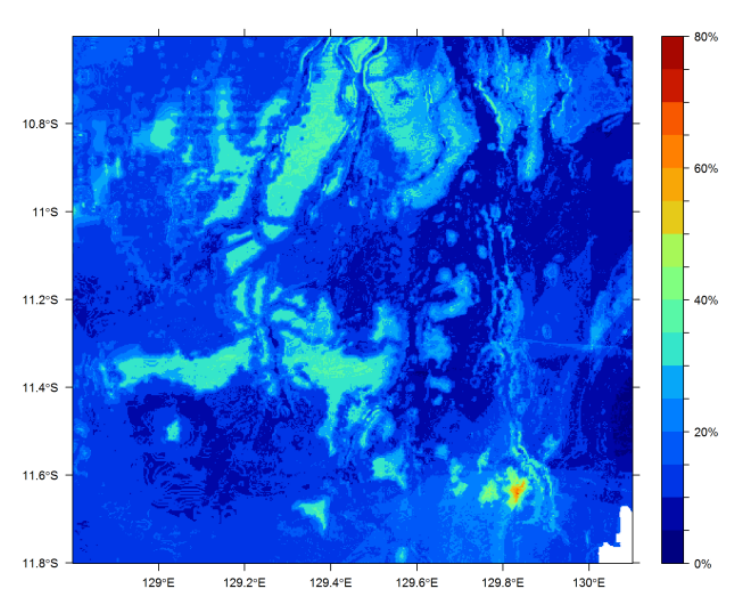

(b)

Figure 1. Predictions of seabed gravel in the Petrel sub-basin, northern Australian marine margin using a hybrid method of random forest and ordinary kriging (RFOK): (a) plotKML (left) and (b) spplot (right). 


\section{Summary}

This study reviewed the modeling process for spatial predictive modeling in environmental sciences. The modeling process covers the following nine components:

1. Sampling design and data preparation;

2. Selection of predictive methods;

3. Pre-selection of predictive variables;

4. Exploratory analysis;

5. Parameter selection;

6. Variable selection;

7. Accuracy assessment;

8. Model validation;

9. Spatial predictions, prediction uncertainty, and their visualization.

Each of these components plays a significant role in model development. Incorrect or inappropriate implementation of any components may lead to less accurate or even misleading predictive model(s). To select the most accurate predictive model, all components and relevant requirements and factors for each component need to be considered and carefully implemented by following the guidelines, suggestions, and recommendations provided under relevant components in this study. Reproducible examples were provided to demonstrate how to select and identify the most accurate spatial predictive model using spm, and to generate and visualize spatial predictions in environmental sciences. For a predictive model, predictive accuracy is a key criterion for model selection and is critical for subsequent spatial predictions. This modeling process is not only important for spatial predictive modeling, but also provides valuable reference to other predictive modeling fields. Although this study attempts to cover relevant components, which may contribute to the improvement of predictive accuracy, as completely as possible, the spatial predictive modeling field is too broad to allow that to be done comprehensively in this study. This is because different disciplines have their own specific features and requirements. Therefore, further studies are needed to identify factors in relevant components or additional components that can further improve the accuracy of predictive models in various disciplines. This study would be expected to not only boost applications of appropriate spatial predictive modeling processes, but also provide spatial predictive modeling tools for various modeling components to improve the quality of spatial predictions.

Funding: This research received no external funding.

Acknowledgments: I would like to thank Gareth Davies, Peter Tan, Trevor Dhu, Andrew Carroll, and Kim Picard for their valuable comments and suggestions. This study was supported by Geoscience Australia. This paper was published with the permission of the Chief Executive Officer, Geoscience Australia.

Conflicts of Interest: The authors declare no conflicts of interest.

\section{References}

1. Marmion, M.; Luoto, M.; Heikkinen, R.K.; Thuiller, W. The performance of state-of-the-art modelling techniques depends on geographical distribution of species. Ecol. Model. 2009, 220, 3512-3520. [CrossRef]

2. Maier, H.R.; Kapelan, Z.; Kasprzyk, J.; Kollat, J.; Matott, L.S.; Cunha, M.C.; Dandy, G.C.; Gibbs, M.S.; Keedwell, E.; Marchi, A.; et al. Evolutionary algorithms and other metaheuristics in water resources: Current status, research challenges and future directions. Environ. Model. Softw. 2014, 62, 271-299. [CrossRef]

3. Li, J.; Heap, A. A Review of Spatial Interpolation Methods for Environmental Scientists; Record 2008/23; Geoscience Australia: Canberra, Australia, 2008; 137p.

4. Stephens, D.; Diesing, M. Towards quantitative spatial models of seabed sediment composition. PLoS ONE 2015, 10, e0142502. [CrossRef] [PubMed] 
5. Sanabria, L.A.; Cechet, R.P.; Li, J. Mapping of australian fire weather potential: Observational and modelling studies. In Proceedings of the 20th International Congress on Modelling and Simulation (MODSIM2013), Adelaide, Australia, 1-6 December 2013; pp. 242-248.

6. Li, J.; Alvarez, B.; Siwabessy, J.; Tran, M.; Huang, Z.; Przeslawski, R.; Radke, L.; Howard, F.; Nichol, S. Application of random forest, generalised linear model and their hybrid methods with geostatistical techniques to count data: Predicting sponge species richness. Environ. Model. Softw. 2017, 97, 112-129. [CrossRef]

7. Hastie, T.; Tibshirani, R.; Friedman, J. The Elements of Statistical Learning: Data Mining, Inference, and Prediction, 2nd ed.; Springer: New York, NY, USA, 2009; p. 763.

8. Crawley, M.J. The R Book; John Wiley \& Sons, Ltd.: Chichester, UK, 2007; p. 942.

9. Kuhn, M.; Johnson, K. Applied Predictive Modeling; Springer: New York, NY, USA, 2013.

10. Li, J.; Heap, A.D. Spatial interpolation methods applied in the environmental sciences: A review. Environ. Model. Softw. 2014, 53, 173-189. [CrossRef]

11. Li, J.; Heap, A. A review of comparative studies of spatial interpolation methods in environmental sciences: Performance and impact factors. Ecol. Inform. 2011, 6, 228-241. [CrossRef]

12. Li, J.; Potter, A.; Huang, Z.; Daniell, J.J.; Heap, A. Predicting Seabed Mud Content across the Australian Margin: Comparison of Statistical and Mathematical Techniques Using a Simulation Experiment; Record 2010/11; Geoscience Australia: Canberra, Australia, 2010; 146p.

13. Sanabria, L.A.; Qin, X.; Li, J.; Cechet, R.P.; Lucas, C. Spatial interpolation of mcarthur's forest fire danger index across australia: Observational study. Environ. Model. Softw. 2013, 50, 37-50. [CrossRef]

14. Tadić, J.M.; Ilić, V.; Biraud, S. Examination of geostatistical and machine-learning techniques as interpolaters in anisotropic atmospheric environments. Atmos. Environ. 2015, 111, 28-38. [CrossRef]

15. Wolpert, D.; Macready, W. No free lunch theorems for optimization. IEEE Trans. Evol. Comput. 1997, 1, 67-82. [CrossRef]

16. Burrough, P.A.; McDonnell, R.A. Principles of Geographical Information Systems; Oxford University Press: Oxford, UK, 1998; p. 333.

17. Jakeman, A.J.; Letcher, R.A.; Norton, J.P. Ten iterative steps in development and evaluation of environmental models. Environ. Model. Softw. 2006, 21, 602-614. [CrossRef]

18. Li, J. Assessing spatial predictive models in the environmental sciences: Accuracy measures, data variation and variance explained. Environ. Model. Softw. 2016, 80, 1-8. [CrossRef]

19. Leek, J.T.; Peng, R.D. What is the question? Science 2015, 347, 1314-1315. [CrossRef]

20. Li, J. spm: Spatial Predictive Modelling. R Package Version 1.1.0. Available online: https://CRAN.R-project. org/package $=$ spm:2018 (accessed on 17 May 2019).

21. Foster, S.D.; Hosack, G.R.; Lawrence, E.; Przeslawski, R.; Hedge, P.; Caley, M.J.; Barrett, N.S.; Williams, A.; Li, J.; Lynch, T.; et al. Spatially balanced designs that incorporate legacy sites. Methods Ecol. Evol. 2017, 8, 1433-1442. [CrossRef]

22. Benedetti, R.; Piersimoni, F.; Postigione, P. Spatially balanced sampling: A review and a reappraisal. Int. Stat. Rev. 2017, 85, 439-454. [CrossRef]

23. Stevens, D.L.; Olsen, A.R. Spatially balanced sampling of natural resources. J. Am. Stat. Assoc. 2004, 99, $262-278$. [CrossRef]

24. Benedetti, R.; Piersimoni, F. A spatially balanced design with probability function proportional to the within sample distance. Biom. J. 2017, 59, 1067-1084. [CrossRef]

25. Wang, J.-F.; Stein, A.; Gao, B.-B.; Ge, Y. A review of spatial sampling. Spat. Stat. 2012, 2, 1-14. [CrossRef]

26. Diggle, P.J.; Ribeiro, P.J., Jr. Model-Based Geostatistics; Springer: New York, NY, USA, 2010; p. 228.

27. Przeslawski, R.; Daniell, J.; Anderson, T.; Vaughn Barrie, J.; Heap, A.; Hughes, M.; Li, J.; Potter, A.; Radke, L.; Siwabessy, J.; et al. Seabed Habitats and Hazards of the Joseph Bonaparte Gulf and Timor Sea, Northern Australia; Record 2008/23; Geoscience Australia: Canberra, Australia, 2011; 69p.

28. Radke, L.C.; Li, J.; Douglas, G.; Przeslawski, R.; Nichol, S.; Siwabessy, J.; Huang, Z.; Trafford, J.; Watson, T.; Whiteway, T. Characterising sediments for a tropical sediment-starved shelf using cluster analysis of physical and geochemical variables. Environ. Chem. 2015, 12, 204-226. [CrossRef]

29. Radke, L.; Nicholas, T.; Thompson, P.; Li, J.; Raes, E.; Carey, M.; Atkinson, I.; Huang, Z.; Trafford, J.; Nichol, S. Baseline biogeochemical data from australia's continental margin links seabed sediments to water column characteristics. Mar. Freshw. Res. 2017. [CrossRef] 
30. Kincaid, T. GRTS Survey Designs for an Area Resource. 2019. Available online: https://cran.r-project.org/ web/packages/spsurvey/vignettes/Area_Design.pdf (accessed on 17 May 2019).

31. Kincaid, T.M.; Olsen, A.R. spsurvey: Spatial Survey Design and Analysis. R Package Version 3.3. 2016. Available online: https://cran.r-project.org/web/packages/spsurvey/index.html (accessed on 17 May 2019).

32. Hengl, T. GSIF: Global Soil Information Facilities. R Package Version 0.4-1. 2014. Available online: https://cran.r-project.org/web/packages/GSIF/index.html (accessed on 17 May 2019).

33. Walvoort, D.J.J. Spatial Coverage Sampling and Random Sampling from Compact Geographical Strata. R Package Version 0.3-6. Available online: https://cran.r-project.org/web/packages/spcosa/index.html (accessed on 17 May 2019).

34. Roudier, P. CLHS: A R Package for Conditioned Latin Hypercube Sampling. 2011. Available online: https://cran.r-project.org/web/packages/clhs/index.html (accessed on 17 May 2019).

35. Grafströn, A.; Lisic, J. Balancedsampling: Balanced and Saptially Balanced Sampling. R Package Version 1.5.4. 2018. Available online: https://cran.r-project.org/web/packages/BalancedSampling/index.html (accessed on 17 May 2019).

36. Radke, L.; Smit, N.; Li, J.; Nicholas, T.; Picard, K. Outer Darwin Harbour Shallow Water Sediment Survey 2016: Ga0356-Post-Survey Report; Record 2017/06; Geoscience Australia: Canberra, Australia, 2017. [CrossRef]

37. Siwabessy, P.J.W.; Smit, N.; Atkinson, I.; Dando, N.; Harries, S.; Howard, F.J.F.; Li, J.; Nicholas, W.A.; Picard, K.; Radke, L.C.; et al. Bynoe Harbour Marine Survey 2016: Ga4452/sol6432—Post-Survey Report; Record 2017/04; Geoscience Australia: Canberra, Australia, 2017.

38. Foster, S.D. MBHdesign: Spatial Designs for Ecological and Environmental Surveys. R Package Version 1.0.76. 2017. Available online: https://cran.r-project.org/web/packages/MBHdesign/index.html (accessed on 17 May 2019).

39. Cai, L.; Zhu, Y. The challenges of data quality and data quality assessment in the big data era. Data Sci. J. 2015, 14, 1-10.

40. Pipino, L.L.; Lee, Y.W.; Wang, R.Y. Data quality assessment. Commun. ACM 2002, 45, 211-218. [CrossRef]

41. Li, J.; Potter, A.; Huang, Z.; Heap, A. Predicting Seabed sand Content across the Australian Margin Using Machine Learning and Geostatistical Methods; Record 2012/48; Geoscience Australia: Canberra, Australia, 2012; 115p.

42. Li, J.; Hilbert, D.W.; Parker, T.; Williams, S. How do species respond to climate change along an elevation gradient? A case study of the grey-headed robin (Heteromyias albispecularis). Glob. Chang. Biol. 2009, 15, 255-267. [CrossRef]

43. Jiang, W.; Li, J. The Effects of Spatial Reference Systems on the Predictive Accuracy of Spatial Interpolation Methods; Record 2014/01; Geoscience Australia: Canberra, Australia, 2014; p. 33.

44. Jiang, W.; Li, J. Are Spatial Modelling Methods Sensitive to Spatial Reference Systems for Predicting Marine Environmental Variables. In Proceedings of the 20th International Congress on Modelling and Simulation, Adelaide, Australia, 1-6 December 2013; pp. 387-393.

45. Turner, A.J.; Li, J.; Jiang, W. Effects of spatial reference systems on the accuracy of spatial predictive modelling along a latitudinal gradient. In Proceedings of the 22nd International Congress on Modelling and Simulation, Hobart, Australia, 3-8 December 2017; pp. 106-112.

46. Purss, M. Topic 21: Discrete Global Grid Systems Abstract Specification, Open Geospatial Consortium [OGC 15-104r5]. 2017. Available online: https://www.google.com.au/url?sa=t\&rct=j\&q=\&esrc=s\&source=web\&cd=4\&cad= rja\&uact=8\&ved=2ahUKEwiHmPmnrqHiAhWFfisKHfTlB18QFjADegQIABAC\&url=https\%3A\%2F\%2Fportal. opengeospatial.org\%2Ffiles\%2F15-104r5\&usg=AOvVaw3Ww2TasQntx17y99VlHwig (accessed on 17 May 2019).

47. Li, J. Predictive modelling using random forest and its hybrid methods with geostatistical techniques in marine environmental geosciences. In Proceedings of the Eleventh Australasian Data Mining Conference (AusDM 2013), Canberra, Australia, 13-15 November 2013; Volume 146.

48. Stephens, D.; Diesing, M. A comparison of supervised classification methods for the prediction of substrate type using multibeam acoustic and legacy grain-size data. PLoS ONE 2014, 9, e93950. [CrossRef] [PubMed]

49. Hengl, T.; Heuvelink, G.B.M.; Kempen, B.; Leenaars, J.G.B.; Walsh, M.G.; Shepherd, K.D.; Sila, A.; MacMillan, R.A.; de Jesus, J.M.; Tamene, L.; et al. Mapping soil properties of africa at $250 \mathrm{~m}$ resolution: Random forests significantly improve current predictions. PLoS ONE 2015, 10, e0125814. [CrossRef] [PubMed]

50. Zhang, X.; Liu, G.; Wang, H.; Li, X. Application of a hybrid interpolation method based on support vector machine in the precipitation spatial interpolation of basins. Water 2017, 9, 760. [CrossRef] 
51. Seo, Y.; Kim, S.; Singh, V.P. Estimating spatial precipitation using regression kriging and artificial neural network residual kriging (rknnrk) hybrid approach. Water Resour. Manag. 2015, 29, 2189-2204. [CrossRef]

52. Demyanov, V.; Kanevsky, M.; Chernov, S.; Savelieva, E.; Timonin, V. Neural network residual kriging application for climatic data. J. Geogr. Inf. Decis. Anal. 1998, 2, 215-232.

53. Appelhans, T.; Mwangomo, E.; Hardy, D.R.; Hemp, A.; Nauss, T. Evaluating machine learning approaches for the interpolation of monthly air temperature at mt. Kilimanjaro, tanzania. Spat. Stat. 2015, 14, 91-113. [CrossRef]

54. Leathwick, J.R.; Elith, J.; Francis, M.P.; Hastie, T.; Taylor, P. Variation in demersal fish species richness in the oceans surrounding new zealand: An analysis using boosted regression trees. Mar. Ecol. Prog. Ser. 2006, 321, 267-281. [CrossRef]

55. Leathwick, J.R.; Elith, J.; Hastie, T. Comparative performance of generalised additive models and multivariate adaptive regression splines for statistical modelling of species distributions. Ecol. Model. 2006, 199, 188-196. [CrossRef]

56. Isaaks, E.H.; Srivastava, R.M. Applied Geostatistics; Oxford University Press: New York, NY, USA, 1989 ; p. 561.

57. Hengl, T. A Practical Guide to Geostatistical Mapping of Environmental Variables; Office for Official Publication of the European Communities: Luxembourg, 2007; p. 143.

58. Pebesma, E.J. Multivariable geostatistics in s: The gstat package. Comput. Geosci. 2004, 30, 683-691. [CrossRef]

59. Bivand, R.S.; Pebesma, E.J.; Gómez-Rubio, V. Applied Spatial Data Analysis with R; Springer: New York, NY, USA, 2008; p. 374.

60. Lark, R.M.; Ferguson, R.B. Mapping risk of soil nutrient deficiency or excess by disjunctive and indicator kriging. Geoderma 2004, 118, 39-53. [CrossRef]

61. Huang, H.; Chen, C. Optimal geostatistical model selection. J. Am. Stat. Assoc. 2007, 102, 1009-1024. [CrossRef]

62. Hernandez-Stefanoni, J.L.; Ponce-Hernandez, R. Mapping the spatial variability of plant diversity in a tropical forest: Comparison of spatial interpolation methods. Environ. Monit. Assess. 2006, 117, 307-334. [CrossRef] [PubMed]

63. Stein, A.; Hoogerwerf, M.; Bouma, J. Use of soil map delineations to improve (co-)kriging of point data on moisture deficits. Geoderma 1988, 43, 163-177. [CrossRef]

64. Voltz, M.; Webster, R. A comparison of kriging, cubic splines and classification for predicting soil properties from sample information. J. Soil Sci. 1990, 41, 473-490. [CrossRef]

65. Bennett, N.D.; Croke, B.F.W.; Guariso, G.; Guillaume, J.H.A.; Hamilton, S.H.; Jakeman, A.J.; Marsili-Libelli, S.; Newham, L.T.H.; Norton, J.P.; Perrin, C.; et al. Characterising performance of environmental models. Environ. Model. Softw. 2013, 40, 1-20. [CrossRef]

66. Gneiting, T.; Balabdaoui, F.; Raftery, A.E. Probabilistic forecasts, calibration and sharpness. J. R. Stat. Soc. Ser. B 2007, 69, 243-268. [CrossRef]

67. Austin, M. Species distribution models and ecological theory: A critical assessment and some possible new approaches. Ecol. Model. 2007, 200,1-19. [CrossRef]

68. Elith, J.; Leathwick, J. Species distribution models: Ecological explanation and prediction across space and time. Annu. Rev. Ecol. Evol. Syst. 2009, 40, 677-697. [CrossRef]

69. McArthur, M.A.; Brooke, B.P.; Przeslawski, R.; Ryan, D.A.; Lucieer, V.L.; Nichol, S.; McCallum, A.W.; Mellin, C.; Cresswell, I.D.; Radke, L.C. On the use of abiotic surrogates to describe marine benthic biodiversity. Estuar. Coast. Shelf Sci. 2010, 88, 21-32. [CrossRef]

70. Huston, M.A. Hidden treatments in ecological experiments: Re-evaluating the ecosystem function of biodiversity. Oecologia 1997, 110, 449-460. [CrossRef]

71. Arthur, A.D.; Li, J.; Henry, S.; Cunningham, S.A. Influence of woody vegetation on pollinator densities in oilseed brassica fields in an australian temperate landscape. Basic Appl. Ecol. 2010, 11, 406-414. [CrossRef]

72. Elith, J.; Graham, C.H.; Anderson, R.P.; Dulik, M.; Ferrier, S.; Guisan, A.; Hijmans, R.J.; Huettmann, F.; Leathwick, J.R.; Lehmann, A.; et al. Novel methods improve prediction of species' distributions from occurrence data. Ecography 2006, 29, 129-151. [CrossRef]

73. Miller, K.; Puotinen, M.; Przeslawski, R.; Huang, Z.; Bouchet, P.; Radford, B.; Li, J.; Kool, J.; Picard, K.; Thums, M.; et al. Ecosystem Understanding to Support Sustainable Use, Management and Monitoring of Marine Assets in the North and North-West Regions: Final Report for NESP d1 2016e; Report to the National Environmental Science Program, Marine Biodiversity Hub; Australian Institute of Marine Science: Townsville, Australia, 2016; 146p. Available online: 
https://www.nespmarine.edu.au/system/files/Miller\%20et\%20al\%20Project\%20D1\%20Report\%20summarising\% 20outputs\%20from\%20synthesis $\% 20$ of $\% 20$ datasets $\% 20$ and $\% 20$ predictive $\% 20$ models $\% 20$ for $\% 20$ N\%20and $\% 20$ NW_ Milestone\%204_RPv3.pdf (accessed on 17 May 2019).

74. Li, J. Predicting the spatial distribution of seabed gravel content using random forest, spatial interpolation methods and their hybrid methods. In Proceedings of the International Congress on Modelling and Simulation (MODSIM) 2013, Adelaide, Austrialia, 1-6 December 2013; pp. 394-400.

75. Verfaillie, E.; Van Lancker, V.; Van Meirvenne, M. Multivariate geostatistics for the predictive modelling of the surficial sand distribution in shelf seas. Cont. Shelf Res. 2006, 26, 2454-2468. [CrossRef]

76. Verfaillie, E.; Du Four, I.; Van Meirvenne, M.; Van Lancker, V. Geostatistical modeling of sedimentological parameters using multi-scale terrain variables: Application along the belgian part of the north sea. Int. J. Geogr. Inf. Sci. 2008. [CrossRef]

77. Huang, Z.; Nichol, S.; Siwabessy, P.J.W.; Daniell, J.; Brooke, B.P. Predictive modelling of seabed sediment parameters using multibeam acoustic data: A case study on the carnarvon shelf, western australia. Int. J. Geogr. Inf. Sci. 2012, 26, 283-307. [CrossRef]

78. Li, J.; Siwabessy, J.; Tran, M.; Huang, Z.; Heap, A. Predicting seabed hardness using random forest in R. In Data Mining Applications with R; Zhao, Y., Cen, Y., Eds.; Elsevier: Amsterdam, The Netherlands, 2014; pp. 299-329.

79. Li, J.; Tran, M.; Siwabessy, J. Selecting optimal random forest predictive models: A case study on predicting the spatial distribution of seabed hardness. PLoS ONE 2016, 11, e0149089. [CrossRef]

80. Siwabessy, P.J.W.; Daniell, J.; Li, J.; Huang, Z.; Heap, A.D.; Nichol, S.; Anderson, T.J.; Tran, M. Methodologies for Seabed Substrate Characterisation Using Multibeam Bathymetry, Backscatter and Video Data: A Case Study from the Carbonate Banks of the Timor Sea, Northern Australia; Record 2013/11; Geoscience Australia: Canberra, Australia, 2013; 82p.

81. Huang, Z.; Brooke, B.; Li, J. Performance of predictive models in marine benthic environments based on predictions of sponge distribution on the australian continental shelf. Ecol. Inform. 2011, 6, 205-216. [CrossRef]

82. Lark, R.M.; Marchant, B.P.; Dove, D.; Green, S.L.; Stewart, H.; Diesing, M. Combining observations with acoustic swath bathymetry and backscatter to map seabed sediment texture classes: The empirical best linear unbiased predi. Sediment. Geol. 2015, 328, 17-32. [CrossRef]

83. Diesing, M.; Mitchell, P.; Stephens, D. Image-based seabed classification: What can we learn from terrestrial remote sensing? ICES J. Mar. Sci. 2016, fsw 118. [CrossRef]

84. Fisher, P.; Wood, J.; Cheng, T. Where is helvellyn? Fuzziness of multi-scale landscape morphometry. Trans. Inst. Br. Geogr. 2004, 29, 106-128. [CrossRef]

85. Zuur, A.; Leno, E.N.; Elphick, C.S. A protocol for data exploration to avoid common statistical problems. Methods Ecol. Evol. 2010, 1, 3-14. [CrossRef]

86. O'Brien, R.M. A caution regarding rules of thumb for variance inflation factors. Qual. Quant. 2007, 41, 673-690. [CrossRef]

87. Harrell, F.E., Jr. Regression modelling strategies: with applications to linear models, logistic regression, and survival analysis; Springer: New York, NY, USA, 1997.

88. Li, J.; Heap, A.D.; Potter, A.; Daniell, J. Application of machine learning methods to spatial interpolation of environmental variables. Environ. Model. Softw. 2011, 26, 1647-1659. [CrossRef]

89. Cutler, D.R.; Edwards, T.C.J.; Beard, K.H.; Cutler, A.; Hess, K.T.; Gibson, J.; Lawler, J.J. Random forests for classification in ecology. Ecography 2007, 88, 2783-2792. [CrossRef]

90. Collins, F.C.; Bolstad, P.V. A comparison of spatial interpolation techniques in temperature estimation. In Proceedings of the Third International Conference/Workshop on Integrating GIS and Environmental Modeling, Santa Fe, NM, USA, 21-25 January 1996.

91. Ripley, B.D. Spatial Statistics; John Wiley \& Sons: New York, NY, USA, 1981; p. 252.

92. Wu, J.; Norvell, W.A.; Welch, R.M. Kriging on highly skewed data for dtpa-extractable soil zn with auxiliary information for ph and organic carbon. Geoderma 2006, 134, 187-199. [CrossRef]

93. Meul, M.; Van Meirvenne, M. Kriging soil texture under different types of nonstationarity. Geoderma 2003, 112, 217-233. [CrossRef]

94. Liaw, A.; Wiener, M. Classification and regression by randomforest. $R$ News 2002, 2, 18-22.

95. Ridgeway, G. gbm: Generalized Boosted Regression Models. R Package Version 2.1.3. 2017. Available online: https://cran.r-project.org/web/packages/gbm/index.html (accessed on 17 May 2019). 
96. Elith, J.; Leathwick, J.R.; Hastie, T. A working guide to boosted regression trees. J. Anim. Ecol. 2008, 77, $802-813$. [CrossRef]

97. Breiman, L.; Friedman, J.H.; Olshen, R.A.; Stone, C.J. Classification and Regression Trees; Belmont: Wadsworth, OH, USA, 1984.

98. Li, J.; Hilbert, D.W. Lives: A new habitat modelling technique for predicting the distributions of species' occurrence using presence-only data based on limiting factor theory. Biodivers. Conserv. 2008, 17, 3079-3095. [CrossRef]

99. Johnson, J.B.; Omland, K.S. Model selection in ecology and evolution. Trends Ecol. Evol. 2004, 19, 101-108. [CrossRef]

100. Venables, W.N.; Ripley, B.D. Modern Applied Statistics with S-Plus, 4th ed.; Springer: New York, NY, USA, 2002; p. 495.

101. Chambers, J.M.; Hastie, T.J. Statistical Models in S; Wadsworth and Brooks/Cole Advanced Books and Software: Pacific Grove, CA, USA, 1992; p. 608.

102. Lumley, T.; Miller, A. leaps: Regression Subset Selection. R Package Version 3.0. 2009. Available online: https://cran.r-project.org/web/packages/leaps/index.html (accessed on 17 May 2019).

103. McLeod, A.I.; Xu, C. bestglm: Best Subset GLM. R Package Version 0.36. 2017. Available online: https: //cran.r-project.org/web/packages/bestglm/index.html (accessed on 17 May 2019).

104. Li, J.; Alvarez, B.; Siwabessy, J.; Tran, M.; Huang, Z.; Przeslawski, R.; Radke, L.; Howard, F.; Nichol, S. Selecting predictors to form the most accurate predictive model for count data. In Proceedings of the International Congress on Modelling and Simulation (MODSIM) 2017, Hobart, Australia, 3-8 December 2017.

105. Kursa, M.B.; Rudnicki, W.R. Feature selection with the boruta package. J. Stat. Softw. 2010, 36, 1-13. [CrossRef]

106. Kuhn, M. caret: Classification and Regression Training. R Package Version 6.0-81. 2018. Available online: https://cran.r-project.org/web/packages/caret/index.html (accessed on 17 May 2019).

107. Genuer, R.; Poggi, J.M.; Tuleau-Malot, C. VSURF: Variable Selection Using Random Forests. R Package Version 1.0.2. 2015. Available online: https://cran.r-project.org/web/packages/VSURF/index.html (accessed on 17 May 2019).

108. Li, J.; Siwabessy, J.; Huang, Z.; Nichol, S. Developing an optimal spatial predictive model for seabed sand content using machine learning, geostatistics and their hybrid methods. Geosciences 2019, 9, 180. [CrossRef]

109. Han, J.; Kamber, M. Data Mining: Concept and Techniques, 2nd ed.; Elsevier: Amsterdam, The Netherlands, 2006; p. 770.

110. Moriasi, D.N.; Arnold, J.G.; Van Liew, M.W.; Bingner, R.L.; Harmel, R.D.; Veith, T.L. Model evaluation guidelines for systematic quantification of accuracy in watershed simulations. Am. Soc. Agric. Biol. Eng. 2007, 50, 885-900.

111. Li, J. Assessing the accuracy of predictive models for numerical data: Not $\mathrm{r}$ nor $\mathrm{r}^{2}$, why not? Then what? PLoS ONE 2017, 12, e0183250. [CrossRef] [PubMed]

112. Allouche, O.; Tsoar, A.; Kadmon, R. Assessing the accuracy of species distribution models: Prevalence, kappa and true skill statistic (tss). J. Appl. Ecol. 2006, 43, 1223-1232. [CrossRef]

113. Fielding, A.H.; Bell, J.F. A review of methods for the assessment of prediction errors in conservation presence/absence models. Environ. Conserv. 1997, 24, 38-49. [CrossRef]

114. Thibaud, E.; Petitpierre, B.; Broennimann, O.; Davison, A.C.; Guisan, A. Measuring the relative effect of factors affecting species distribution model predictions. Methods Ecol. Evol. 2014, 5, 947-955. [CrossRef]

115. Lobo, J.M.; Jiménez-Valverde, A.; Real, R. Auc: A misleading measure of the performance of predictive distribution models. Glob. Ecol. Biogeogr. 2008, 7, 145-151. [CrossRef]

116. Kohavi, R. A study of cross-validation and bootstrap for accuracy estimation and model selection. In Proceedings of the International Joint Conference on Artificial Intelligence (IJCAI), Montreal, QC, Canada, 20-25 August 1995; pp. 1137-1143.

117. Refsgaard, J.C.; van der Sluijs, J.P.; Højberg, A.L.; Vanrolleghem, P.A. Uncertainty in the environmental modelling process - a framework and guidance. Environ. Model. Softw. 2007, 22, 1543-1556. [CrossRef]

118. Hayes, K.R. Uncertainty and Uncertainty Analysis Methods; CSIRO: Canberra, Australia, 2011 ; p. 131. Available online: https://publications.csiro.au/rpr/download?pid=csiro:EP102467\&dsid=DS3 (accessed on 17 May 2019).

119. Barry, S.; Elith, J. Error and uncertainty in habitat models. J. Appl. Ecol. 2006, 43, 413-423. [CrossRef] 
120. Oxley, T.; ApSimon, H. A conceptual framework for mapping uncertainty in integrated assessment. In Proceedings of the 19th International Congress on Modelling and Simulation, Perth, Australia, 12-16 December 2011.

121. Walker, W.E.; Harremoes, P.; Rotmans, J.; Van der Sluijs, J.P.; van Asselt, M.B.A.; Janssen, P.; Krayer von Krauss, M.P. Defining uncertainty: A conceptual basis for uncertainty management in model-based decision support. Integr. Assess. 2003, 4, 5-17. [CrossRef]

122. Goovaerts, P. Geostatistics for Natural Resources Evaluation; Oxford University Press: New York, NY, USA, 1997; p. 483.

123. Mentch, L.; Hooker, G. Quantifying uncertainty in random forests via confidence intervals and hypothesis tests. J. Mach. Learn. Res. 2016, 17, 1-41.

124. Slaets, J.I.F.; Piepho, H.-P.; Schmitter, P.; Hilger, T.; Cadisch, G. Quantifying uncertainty on sediment loads using bootstrap confidence intervals. Hydrol. Earth Syst. Sci. 2017, 21, 571-588. [CrossRef]

125. Wager, S.; Hastie, T.; Efron, B. Confidence intervals for random forests: The jackknife and the infinitesimal jackknife. J. Mach. Learn. Res. 2014, 15, 1625-1651. [PubMed]

126. Wright, M.N.; Ziegler, A. Ranger: A fast implementation of random forests for high dimensional data in $\mathrm{c}++$ and r. J. Stat. Softw. 2017, 77, 1-17. [CrossRef]

127. Coulston, J.W.; Blinn, C.E.; Thomas, V.A.; Wynne, R.H. Approximating prediction uncertainty for random forest regression models. Photogramm. Eng. Remote Sens. 2016, 82, 189-197. [CrossRef]

128. Chen, J.; Li, M.-C.; Wang, W. Statistical uncertainty estimation using random forests and its application to drought forecast. Math. Probl. Eng. 2012, 2012, 915053. [CrossRef]

129. Bishop, T.F.A.; Minasny, B.; McBratney, A.B. Uncertainty analysis for soil-terrain models. Int. J. Geogr. Inf. Sci. 2006, 20, 117-134. [CrossRef]

130. Hijmans, R.J. raster: Geographic Data Analysis and Modeling. Available online: http://CRAN.R-project.org/ package=raster (accessed on 17 May 2019).

(C) 2019 by the author. Licensee MDPI, Basel, Switzerland. This article is an open access article distributed under the terms and conditions of the Creative Commons Attribution (CC BY) license (http://creativecommons.org/licenses/by/4.0/). 